AOGS MAIN RESEARCH ARTICLE

\title{
The effects of counseling on fear of childbirth
}

\author{
BIRGITTA LARSSON ${ }^{1,2}$, ANNIKA KARLSTRÖM ${ }^{3}$, CHRISTINE RUBERTSSON ${ }^{1}$ \& INGEGERD \\ HILDINGSSON $1,3,4$
}

\begin{abstract}
${ }^{1}$ Department of Women's and Children's Health, Uppsala University, Uppsala, ${ }^{2}$ Research and Development Centre, Sundsvall Hospital, Sundsvall, ${ }^{3}$ Department of Nursing Sciences, Mid-Sweden University, Sundsvall, and ${ }^{4}$ Women's and Children's Health, Department of Reproductive Health, Karolinska Institute, Stockholm, Sweden
\end{abstract}

\section{Key words}

Birth experience, childbirth fear, cesarean section, counseling, support

\section{Correspondence}

Birgitta Larsson, Department of Women's and Children's Health, Akademiska sjukhuset, 75185 Uppsala, Sweden.

E-mail: birgitta.larsson@kbh.uu.se

\section{Conflicts of interest}

The authors have stated explicitly that there are no conflicts of interest in connection with this article.

Please cite this article as: Larsson B, Karlström A, Rubertsson C, Hildingsson I. The effects of counseling on fear of childbirth. Acta Obstet Gynecol Scand 2015; 94: 629-636.

Received: 24 July 2014

Accepted: 10 March 2015

DOI: 10.1111/aogs.12634
Objective. To investigate women's experiences of attending existing counseling programs for childbirth-related fear and the effect of this counseling over time. Design. A longitudinal survey. Setting. Three hospitals in the central north of Sweden. Sample. A selected sample of 936 women. Of these, 70 received counseling due to fear of childbirth (study-group). Methods. Data were collected with questionnaires 2 months and 1 year after giving birth with background data collected during midpregnancy. Comparisons were made between women with or without counseling. Crude and adjusted odds ratios (OR) were calculated. Main outcome measures. Self-reported childbirth fear, experience of counseling, birth experience and preferred mode of birth. Results. Women in the counseling group reported higher childbirth fear 1 year after giving birth (OR 5.0, 95\% confidence interval (95\% CI) 2.6-9.3), they had a more negative birth experience that did not change over time (OR 2.1, 95\% CI 1.2-3.9) and they preferred cesarean section to a greater extent (OR 12.0, 95\% CI 5.1-28.1) in the case of another birth. Also, they were more often delivered by planned cesarean section (OR 4.7, 95\% CI 2.4-9.1). However, 80\% were satisfied with the given support. Conclusion. Although women were satisfied with the treatment, this study shows that counseling had a minor effect on fear of childbirth, birth experiences or cesarean section rates. To help women with their fear of childbirth, more effective methods of treatment are needed.

Abbreviations: $\mathrm{CI}$, confidence interval; OR, odds ratio.

\section{Introduction}

Childbirth fear is strongly related to subsequent reproduction and women's and children's health. The majority of studies on fear of childbirth have focused on maternal characteristics and the reasons behind this condition. Fewer studies have addressed treatment options. The standard care for women with childbirth-related fear in Sweden is usually counseling with specially trained teams of midwives and obstetricians and sometimes such counseling leads to an elective cesarean section. There are few general guidelines that describe how the counseling teams should work and there is lack of consensus about the best way to perform treatment.

Fear of childbirth affects $6-10 \%$ of pregnant women (1-3) and planned cesarean section without medical reason is more common among women who have this condition (4,5). A Swedish study shows that $8.2 \%$ of pregnant women reported a wish for a planned cesarean section. The most common reasons given were fear of childbirth, a previous negative birth experience and previous cesarean section (6).

\section{Key Message}

Existing counseling programs aiming to reduce fear of childbirth, showed no effect on childbirth fear, the experience of birth or for reducing cesarean section rates. Further research is needed to find more effective methods for treating women with a fear of childbirth. 
In previous research, different types of treatment have been used in order to reduce childbirth-related fear. Sjögren's follow-up study of women who had received psychotherapy in combination with relaxation therapy showed that women in the study group had a birth experience that was similar to those in the reference group. Women who had a vaginal birth after initially having desired elective cesarean section were as satisfied as those who had not expressed a wish for cesarean section (7). Saisto et al. compared cognitive therapy and conventional therapy. Both methods reduced unnecessary cesarean sections, but no reduction in childbirth fear was shown (8). Saisto et al. have also explored group therapy with a psychological understanding combined with relaxation in nulliparous women. The trial resulted in more women having a spontaneous vaginal birth compared with conventional therapy, and the cesarean section rate decreased (9). A randomized controlled study by Rouhe et al. showed that the same group therapy as above also had a positive effect for women's birth experience and their childbirth fear decreased (10). Nerum et al. found that individualized crisis-oriented counseling for women with childbirth fear and a wish for cesarean section resulted in $86 \%$ of the participants changing their wishes, and satisfaction with the decision was high (11). In a further analysis of the study mentioned above, Halvorsen et al. found that the attitudes and the counseling approach affected women's propensity to change their preferences about mode of birth. A coping attitude of the counselor was strongly associated with change in the desire for a cesarean section (12). Ryding et al. made an evaluation of midwives' counseling of women with childbirth fear and showed that treated women had a more frightening birth experience, but they were satisfied with the given care (13).

In most Swedish hospitals, women who express childbirth fear are offered counseling and treatment. Screening for childbirth fear is recommended by the Swedish National Board of Health and Welfare in their report, Indication for Cesarean Section on the Mother's Request (14), but no national guidelines for screening have yet been designed. The counseling is initially characterized by an informal conversation where the women talk about their thoughts and feelings about being pregnant and giving birth. Among parous women previous birth experiences are central to the dialogue. Usually there are specially trained midwives who meet the women on two to four occasions. When needed there is collaboration with obstetricians, psychologists, social workers and sometimes psychiatrists. The goal of the counseling teams is to reduce the fear and make the birth experience as positive as possible, regardless of the mode of birth. By support, information and preparation for childbirth, the woman may be strengthened in her belief in herself and her ability to give birth. Parous women with a negative birth experience need support to understand what happened in the previous birth, and to accept and reconcile themselves with the birth experience and the feelings it brought (15). However, support and treatment are differently organized in different hospitals and the effect of this treatment has not been fully investigated (13).

Given that the majority of hospitals in Sweden have introduced counseling as a treatment for childbirth fear without evidence of its effectiveness, the aim of this project was to investigate women's experiences of attending these programs for childbirth-related fear in three hospitals in Sweden and the effect of this counseling over time.

\section{Material and methods}

This study is one part of a regional longitudinal survey of women's expectations and experiences of pregnancy, childbirth and the first year after giving birth. For the purposes of this study, a selected sample of 936 women was chosen. The sample group completed information about counseling 2 months after giving birth and provided background information at midpregnancy and follow-up information 1 year after giving birth. Detailed information about the longitudinal survey is presented elsewhere (16).

The women were recruited in midpregnancy at a routine examination in the ultrasound units of three hospitals in the central north of Sweden during 2007. Two weeks before they were sent information and an invitation to participate in a longitudinal study. After the examination, Swedish-speaking women with a normal ultrasound examination were asked by the ultrasound midwife who performed the examination if they were willing to participate in the survey. Women who agreed to participate signed a consent form and received the first questionnaire to answer directly or take home and return later in a stamped envelope. Two reminder letters were sent to nonresponders after 2 and 4 weeks. The three following questionnaires were sent to the women's home address at 32-34 weeks of gestation, 2 months after giving birth and 1 year after giving birth, with two similar reminders for nonresponders.

A total of 2512 women had the routine ultrasound examination in 2007 of whom 2347 were eligible for participation. Of 1506 women who consented to participate, 936 completed the third questionnaire 2 months after giving birth. The 1-year follow-up questionnaires were sent to 886 women who had completed all three previous questionnaires and 763 responded (Figure 1).

Nonconsenting women were more likely to be $<25$ years $(p<0.001)$ or $>35$ years $(p<0.01)$. They were 


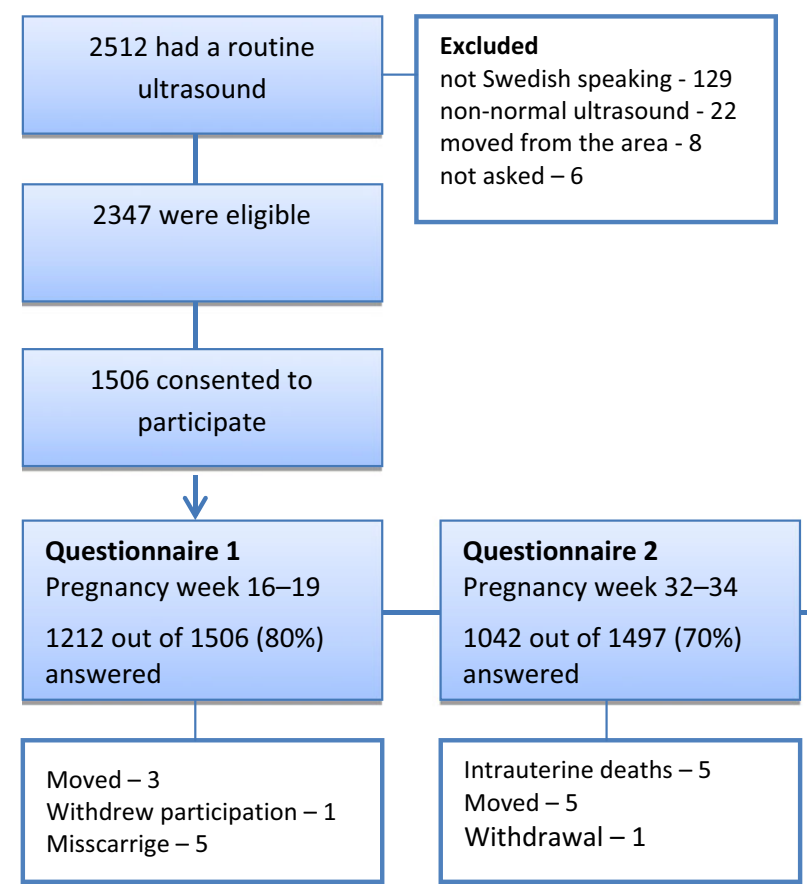

Figure 1. Flow-chart of recruitment and participation.

also more often parous $(p<0.05)$, not living with a partner $(p<0.05)$, born in a country other than Sweden $(p<0.05)$, smokers $(p<0.001)$ and less likely to have a university education $(p<0.001)$. The characteristics of women who considered participating but did not return the questionnaires were similar to the nonconsenting women with the additional factor of unemployment $(p<0.001)$.They were also more likely to have a cesarean section on maternal request $(p<0.01)$ compared with those women who remained in the study. Data regarding the nonconsenting and nonparticipating women are based on the number of mailings and notes made by the ultrasound midwives.

Background data were collected in midpregnancy and the women were asked about their sociodemographic status (age, civil status, country of birth, level of education, smoking status) and obstetric background as parity, previous birth modes and infertility problems. The women had the possibility to give several alternatives regarding previous births. Also women's self-rated childbirth fear and preferences for mode of birth were collected from this first questionnaire. The question regarding childbirth fear was: "Worries and fears are common feelings among women when facing childbirth. To what extent do you experience worry and fear at present?" The women answered using a four-point rating scale ranging from "a great deal" to "not at all." In the analysis the variables were dichotomized into "a great deal/very much" and "somewhat/not at all." One year after giving birth the question was repeated and slightly rephrased: "Worries and fears are common feelings among women when facing childbirth. To what extent do you experience worry and fear when thinking of a future birth?" The women were asked to indicate their preferred mode of birth in midpregnancy by the question: "If you had the possibility to choose, how would you prefer to give birth to your baby?" The response alternatives were "vaginal birth" or "cesarean section." One year after giving birth the question was repeated and slightly rephrased: "If you consider having more children, which mode of birth would you prefer?" and the option "I cannot think of having more children" was added.

Two months after birth, information about the actual birth was collected and this included questions regarding mode of birth, counseling and the birth experience. The women were asked about birth mode and data were also checked for accuracy in the birth records. The question about counseling was: "Did you receive counseling due to fear of giving birth," with the response alternatives, "yes" and "no." If the participants answered "yes," they were given additional questions about who performed the counseling and their level of satisfaction. The birth experience was assessed on a five-point scale ranging from "very positive" to "very negative" 2 months and 1 year after giving birth. In the analysis, the variables were dichotomized into very positive/positive and mixed feel- 
ings/negative/very negative. This dichotomization was based on the skewed nature of the data, with very few women reporting negative birth experiences.

The questionnaires included previously used questions from a national survey of Swedish-speaking women modified for the present study (17). All questionnaires were validated in a pilot study with 12 pregnant women and only minor wording changes were made.

\section{Data analysis}

Descriptive statistics were used to describe the sample. For comparisons between women with or without counseling, crude and adjusted odds ratios (OR) with 95\% CI were calculated (18). A $p$-value (two-sided) $<0.05$ was interpreted as significant. To investigate change in childbirth fear over time Friedman's test was used (18). Statistical analyses were conducted using the Statistical Package for Social sciences, SPSS, version 20.0. The study was approved by the Regional Research and Ethics Committee at Umeå University, Sweden (Dnr 05-134 Ö).

\section{Results}

Two months after giving birth 70 women (7.5\%) out of 936 participants reported that they underwent counseling due to childbirth fear. A majority, 40 of the 70 women, were given counseling support by a specially trained midwife. The regular antenatal midwife gave counseling to 21 of the 70 women. Four women were given counseling support by obstetricians, one woman was treated by a psychologist and two women met a social worker for support. Satisfaction with the given support was high; 56 of the 70 women reported on a five-point rating scale, that they were satisfied or very satisfied.

The majority of women were between the ages of 25 and 35 years, born in Sweden, married or cohabiting and had a college or university degree. Fifty-five per cent of the women were parous and $45 \%$ were nulliparous. There were no significant differences in age, civil status, level of education, smoking status or infertility problems between women who were given counseling and those who were not. Women who underwent counseling were more likely to be born outside Sweden. Childbirth fear during pregnancy occurred in both groups but was significantly higher in the counseling group $(69.1 \%$ vs. $7.8 \%)$. Furthermore, it was almost 10 times more common that the women in the counseling group preferred to be delivered by elective cesarean section (Table 1).

Table 2 shows that parous women who received counseling were five times more likely to have had a previous emergency cesarean section compared with women not receiving counseling due to childbirth fear. Also, previous vaginal birth was negatively associated with receiving counseling in the present pregnancy.

Women who received counseling due to childbirth fear were more often delivered by planned cesarean section, $21.4 \%$ vs. $5.8 \%$. There were no differences between the groups regarding instrumental birth or emergency cesarean section (Table 3 ).

Table 4 shows that women who received counseling were still more fearful after 1 year than women without counseling; $40.7 \%$ compared with $13 \%$. There was no significant change in fear from midpregnancy to 1 year after birth $(p=0.198)$. Women who received counseling expressed more negative birth experiences compared with the group without counseling 2 months after giving birth (not in table, adjusted OR 2.0, 95\% CI 1.2-3.3). This association remained 1 year after birth. In addition, they preferred cesarean section to a greater extent in the case of another birth and it was three times more likely that the women in the counseling group did not want to have more children. The differences between the groups were significant. The associations remained significant after adjusting for parity, mode of birth and country of birth.

\section{Discussion}

The main findings of this study were that although women were satisfied with the counseling they received because of childbirth fear, the fear remained 1 year after birth. Women who received counseling reported a more negative birth experience and preferred a cesarean section in the case of a subsequent pregnancy. Also, it was more likely that they did not want to have more children. Women in the counseling group reported childbirth fear to a greater extent, which was not surprising. A more surprising result was that as many as $31 \%$ in the counseling group reported no fear or fear to some extent during pregnancy. Also, almost $8 \%$ of the women with severe childbirth fear did not receive counseling. This result raises questions about the indication for referrals to the counseling team. Somehow there seems to be a misjudgment when women are offered counseling and there might be a misuse of the supportive teams, as previously shown in a national cohort of women where counseling was associated with more cesarean sections (17). Also, Nyberg et al. showed in their study that midwives working with the counseling programs sometimes view themselves as providing the "ticket to a cesarean" (19).

It is not known if women were exposed to screening procedures during their antenatal care to identify childbirth fear. By screening for childbirth fear, it is possible to distinguish women in need of treatment. The Swedish National Board of Health and Welfare in their report, Indication for Cesarean Section on the Mother's 
Table 1. Sociodemographic and obstetric background data collected in midpregnancy.

\begin{tabular}{|c|c|c|c|c|c|c|}
\hline & \multicolumn{2}{|c|}{$\begin{array}{l}\text { Received counseling } \\
(n=70)\end{array}$} & \multicolumn{2}{|c|}{$\begin{array}{l}\text { Did not receive } \\
\text { counseling }(n=866)\end{array}$} & \multirow[b]{2}{*}{ OR } & \multirow[b]{2}{*}{$95 \% \mathrm{Cl}$} \\
\hline & $n$ & $\%$ & $n$ & $\%$ & & \\
\hline \multicolumn{7}{|l|}{ Age (years) } \\
\hline$<25$ & 7 & 10 & 104 & 12.8 & 0.8 & $0.3-1.7$ \\
\hline $25-35$ & 50 & 71.4 & 565 & 69.3 & 1.0 & Ref. \\
\hline$>35$ & 13 & 18.6 & 146 & 17.9 & 1.0 & $0.5-1.9$ \\
\hline \multicolumn{7}{|l|}{ Parity } \\
\hline Nulliparous & 25 & 36 & 387 & 47.5 & 1.0 & Ref. \\
\hline Multiparous & 45 & 64 & 428 & 52.5 & 1.6 & $1.0-2.7$ \\
\hline \multicolumn{7}{|l|}{ Country of birth } \\
\hline Sweden & 62 & 88.6 & 781 & 95.8 & 1.0 & Ref. \\
\hline Other & 8 & 11.4 & 34 & 4.2 & $3.0 * *$ & $1.3-6.7$ \\
\hline \multicolumn{7}{|l|}{ Civil status } \\
\hline Living with partner & 67 & 95.7 & 792 & 97.2 & 1.0 & Ref. \\
\hline Living without partner & 70 & 4.3 & 23 & 2.8 & 1.5 & $0.5-5.3$ \\
\hline \multicolumn{7}{|l|}{ Education } \\
\hline College/university & 43 & 63.2 & 442 & 54.8 & 1.0 & Ref. \\
\hline Primary/high school & 25 & 36.8 & 364 & 45.2 & 0.7 & $0.4-1.2$ \\
\hline \multicolumn{7}{|l|}{ Smoking } \\
\hline Yes & 4 & 5.7 & 43 & 5.3 & 1.1 & $0.4-3.1$ \\
\hline No & 66 & 94.3 & 772 & 94.7 & 1.0 & Ref. \\
\hline \multicolumn{7}{|l|}{ Infertility problem } \\
\hline Yes & 9 & 13.2 & 98 & 12.2 & 0.9 & $0.4-1.9$ \\
\hline No & 59 & 86.8 & 706 & 87.8 & 1.0 & Ref. \\
\hline \multicolumn{7}{|l|}{ Childbirth fear } \\
\hline Somewhat/not at all & 21 & 30.9 & 742 & 92.2 & 1.0 & Ref. \\
\hline Great deal/very much & 47 & 69.1 & 63 & 7.8 & $26.4 * * *$ & $14.8-46.9$ \\
\hline \multicolumn{7}{|l|}{ Preferred mode of birth } \\
\hline Vaginal & 46 & 68.7 & 757 & 95.6 & 1.0 & Ref. \\
\hline Planned cesarean section & 21 & 31.3 & 35 & 4.4 & $9.9 * * *$ & $5.3-18.3$ \\
\hline
\end{tabular}

$* * p<0.01 ; * * * p<0.001$.

Table 2. Previous birth mode; multiparous only, several options available ${ }^{a}$ : data collected in midpregnancy $(n=473)$.

\begin{tabular}{|c|c|c|c|c|c|c|}
\hline & \multicolumn{2}{|c|}{$\begin{array}{l}\text { Received counseling } \\
(n=45)\end{array}$} & \multicolumn{2}{|c|}{$\begin{array}{l}\text { Did not receive } \\
\text { counseling }(n=428)\end{array}$} & \multirow[b]{2}{*}{ OR } & \multirow[b]{2}{*}{$95 \% \mathrm{Cl}$} \\
\hline & $n$ & $\%$ & $n$ & $\%$ & & \\
\hline Any normal vaginal birth & 25 & 55.6 & 348 & 81.3 & $0.3^{* * *}$ & $0.2-0.5$ \\
\hline Any instrumental birth & 11 & 24.4 & 67 & 15.7 & 1.7 & $0.8-3.6$ \\
\hline Any planned cesarean section & 2 & 4.4 & 27 & 6.3 & 0.7 & $1.6-3.0$ \\
\hline Any emergency cesarean section & 13 & 28.9 & 32 & 7.5 & $5.0 * * *$ & $2.4-10.5$ \\
\hline
\end{tabular}

${ }^{a}$ Reference women not exposed to the studied variable.

$* * * p<0.001$.

Request, recommend routine screening for fear of childbirth in early pregnancy at the antenatal clinic. The screening instrument should be simple and easy to use, with a high degree of compliance (14). The best known measuring instrument is the Wijma Delivery Expectancy/ Experience Questionnaire (WDEQ), which is a comprehensive questionnaire containing 33 items (20). However, it has been criticised for being too complicated for clinical use (21). Rouhe et al. used both the WDEQ and a visual analogue scale to measure fear of childbirth and found that the this scale was useful for prenatal screening, as well as for a follow up after birth (21). Haines et al. proceeded to develop a simple and reliable screening method. By using two visual analogue scales, they 
Table 3. Birth outcomes in the actual birth; data collected 2 months after birth.

\begin{tabular}{|c|c|c|c|c|c|c|}
\hline & \multicolumn{2}{|c|}{$\begin{array}{l}\text { Received counseling } \\
(n=70)\end{array}$} & \multicolumn{2}{|c|}{$\begin{array}{l}\text { Did not receive } \\
\text { counseling }(n=866)\end{array}$} & \multirow[b]{2}{*}{ OR } & \multirow[b]{2}{*}{$95 \% \mathrm{Cl}$} \\
\hline & $n$ & $\%$ & $n$ & $\%$ & & \\
\hline Normal vaginal birth & 41 & 58.6 & 603 & 73.8 & 1.0 & Ref. \\
\hline Instrumental birth & 4 & 5.7 & 79 & 9.7 & 0.7 & $0.3-2.1$ \\
\hline Planned cesarean section & 15 & 21.4 & 47 & 5.8 & $4.7 * * *$ & $2.4-9.1$ \\
\hline Emergency cesarean section & 10 & 14.3 & 88 & 10.8 & 1.7 & $0.8-3.5$ \\
\hline
\end{tabular}

$* * * p<0.001$.

Table 4. Associated factors between counseling during pregnancy and childbirth fear, birth experience and preferred birth mode 1 year after birth.

\begin{tabular}{|c|c|c|c|c|c|c|c|c|}
\hline & \multicolumn{2}{|c|}{$\begin{array}{l}\text { Received } \\
\text { counseling } \\
(n=59)\end{array}$} & \multicolumn{2}{|c|}{$\begin{array}{l}\text { Did not } \\
\text { receive } \\
\text { counseling } \\
(n=704)\end{array}$} & \multirow[b]{2}{*}{ Crude OR } & \multirow[b]{2}{*}{$95 \% \mathrm{Cl}$} & \multirow[b]{2}{*}{ Adjusted $\mathrm{OR}^{\mathrm{a}}$} & \multirow[b]{2}{*}{$95 \% \mathrm{Cl}$} \\
\hline & $n$ & $\%$ & $n$ & $\%$ & & & & \\
\hline \multicolumn{9}{|l|}{ Birth experience } \\
\hline Very positive/positive & 29 & 49.2 & 434 & 65.5 & 1.0 & Ref. & 1.0 & Ref. \\
\hline Mixed feelings/negative/very negative & 30 & 50.8 & 229 & 34.5 & $2.0 *$ & $1.1-3.3$ & $2.1 *$ & $1.2-3.9$ \\
\hline \multicolumn{9}{|l|}{ Childbirth fear } \\
\hline Somewhat/not at all & 35 & 59.3 & 577 & 87.0 & 1.0 & Ref. & 1.0 & Ref. \\
\hline Great deal/very much & 24 & 40.7 & 86 & 13.0 & $4.6 * * *$ & $2.6-8.1$ & $5.0 * * *$ & $2.6-9.3$ \\
\hline \multicolumn{9}{|c|}{ Preferred mode of birth in case of another pregnancy } \\
\hline Vaginal & 26 & 44.1 & 557 & 84.0 & 1.0 & Ref. & 1.0 & Ref. \\
\hline Planned cesarean section & 21 & 36.2 & 48 & 7.2 & $9.3^{* * *}$ & $4.9-17.8$ & $12.0 * * *$ & $5.1-28.1$ \\
\hline I cannot think of having more children & 11 & 19 & 58 & 8.8 & $4.0 * * *$ & $1.9-8.6$ & $3.3^{* *}$ & $1.5-7.4$ \\
\hline
\end{tabular}

${ }^{a}$ Adjusted for parity, country of birth and birth mode.

$* p<0.05 ; * *<0.01 ; * * * p<0.001$.

designed the Fear of Birth Scale, which has been shown to have good validity in both Swedish- and Englishspeaking settings (22).

Most of the women who underwent counseling were satisfied with the given support, which was mainly provided by specially trained midwives, in line with a previous Swedish study (13). However, even though they were satisfied with the given support, after 1 year these women were still five times more fearful than women in the group without counseling. This finding indicates that the counseling support these women received had no or at best a moderate effect on their childbirth-related fear. The decrease in the number of women reporting childbirth fear in the counseling group from midpregnancy to 1 year after giving birth could not be confirmed using Friedman's test and might be a result of the reduced number of participants in the 1 year follow-up questionnaire.

There was a strong association between cesarean section as a preferred birth mode for a future birth and having received counseling due to childbirth fear. An explanation may be the high rate of planned cesarean section in this group. It is known from previous studies that the main reasons for requesting a cesarean section without medical reason is a previous cesarean and childbirth fear $(6,23)$. Therefore, it is important to try to avoid the first cesarean section. Nerum et al. showed that $86 \%$ of fearful women with a request for cesarean section changed their wish of birth mode after crisis-oriented counseling. These women were satisfied with their decision, as opposed to those who maintained their desire for cesarean section. In the follow-up questionnaire after 24 years, $93 \%$ of the responders who had given birth vaginally stated that they would prefer a vaginal birth in the future (11).

It was three times more common that the women in the counseling group did not want to have any more children. This finding could be a choice simply because they already had the desired number of children. On the other hand, this can also be a result of a negative birth experience, which is in line with a previous study showing that a negative birth experience was associated with fewer subsequent children (24). 
Women in the counseling group expressed a more negative birth experience compared with women without counseling, even though they received support for their fear during pregnancy, which confirms the study by Ryding et al. (13). Their negative feelings did not change over time. Further, it has been shown that a woman's self-efficacy affects both her birth experience and the presence of childbirth fear, which may be related to the findings in this study. Childbirth fear is associated with low self-efficacy $(25,26)$ and strong self-efficacy beliefs predict decreased pain and distress in labor and increased birth satisfaction (27). Improved self-efficacy may be one way to reduce childbirth fear and make the birth experience more positive. An Australian pilot study showed that mindfulness-based childbirth education significantly increased self-efficacy and decreased fear of childbirth (28). By developing and offering support programs that improve women's self-efficacy, it is possible to give fearful women confidence in themselves and their ability to give birth. This can be a way to avoid the first cesarean section and give the woman a positive birth experience. This will benefit the woman in a future pregnancy and birth as in life in general. Further, the results from this study suggest that a previous vaginal birth protects women from the need for counseling due to childbirth fear, which is in line with a previous Australian study (29).

This study was compromised by its observational design and the high dropout rate, which may be related to the multiple questionnaires and the busy lives of new mothers. Compared with other self-report questionnaire studies on psychosocial aspects of birth the response rates were, however, quite favorable (30). Another limitation was the large number of women who decided not to participate. The midwives were informed that it would be valuable to provide notification about the number of women who were not approached, but these numbers could lack validity. In addition, the study was designed to assess the experiences and expectations of all pregnant women; so questions did not focus specifically on counseling for childbirth fear.

The dropout rate and the decision of the research team not to send the fourth questionnaire to those who did not respond to the first three questionnaires, could have affected the results, given that fewer women who received counseling responded to the fourth questionnaire. Also, the nonresponders were similar in characteristics to women with childbirth fear reported in previous studies $(17,31)$, which means that there is a possibility that the prevalence of fear of childbirth and counseling could be higher than reported. There was also an exclusion of nonSwedish-speaking women, which may have compromised the results. This study showed that women born outside Sweden were overrepresented among women with child- birth-related fear. We know from a previous Swedish study that requests for a planned cesarean section are more common among foreign-born, non-Nordic women (23).

Another limitation is how childbirth fear was assessed by a four-point rating scale that was further dichotomized, and this could have compromised the findings. The strength of the present study was the longitudinal design which makes it possible to compare groups over time and allows follow up of women's experiences of childbirth.

\section{Conclusions}

Although women were satisfied with the given support, the study shows that counseling had a minor effect on fear of childbirth and birth experience, which means that counseling actually did not work as it was intended. Further, the treatment did not affect the cesarean section rate. An improved and individualized counseling program would benefit both the woman as an individual and women's health from a public health perspective. A few studies have shown evidence of the efficacy of specific treatments, but more research is needed.

\section{References}

1. Areskog B, Uddenberg N, Kjessler B. Fear of childbirth in late pregnancy. Gynecol Obstet Invest. 1981;12:262-6.

2. Rouhe H, Salmela-Aro K, Gissler M, Halmesmäki E, Saisto T. Mental health problems common in women with fear of childbirth. BJOG. 2011;118:1104-11.

3. Storkesen H, Eberhard-Gran M, Garthus-Niegel S, Eskild A. Fear of childbirth; the relation to anxiety and depression. Acta Obstet Gynecol Scand. 2012;91:237-42.

4. Saisto T, Halmesmäki E. Fear of childbirth: a neglected dilemma. Acta Obstet Gynecol Scand. 2003;82:201-8.

5. Sydsjö G, Sydsjö A, Gunnervik C, Bladh M, Josefsson A. Obstetric outcome for women who received individualized treatment for fear of childbirth during pregnancy. Acta Obstet Gynecol Scand. 2012;91:44-9.

6. Hildingsson I, Rådestad I, Rubertsson C, Waldenström U. Few women wish to be delivered by caesarean section. BJOG. 2002;109:618-23.

7. Sjögren B. Fear of childbirth and psychosomatic support. Acta Obstet Gynecol Scand. 1998;77:819-25.

8. Saisto T, Salmela-Aro K, Nurmi J, Könönen T, Halmesmäki E. A randomized controlled trial of intervention in fear of childbirth. Obstet Gynecol. 2001;98:820-6.

9. Saisto T, Toivanen R, Salmela-Aro K, Halmesmäki E. Therapeutic group psychoeducation and relaxation in treating fear of childbirth. Acta Obstet Gynecol Scand. 2006;85:1315-9.

10. Rouhe H, Salmela-Aro K, Toivanen R, Tokola M, Halmesmäki E, Saisto T. Obstetric outcome after 
intervention for severe fear of childbirth in nulliparous women - randomized trial. BJOG. 2013;120:75-84.

11. Nerum H, Halvorsen L, Sörlie T, Öian P. Maternal request for cesarean section due to fear of childbirth: can it be changed through crisis-orientated counseling? Birth. 2006;33:221-8.

12. Halvorsen L, Nerum H, Sörlie T, Öian P. Does counsellor's attitude influence change in a request for a caesarean in women with fear of birth? Midwifery. 2010;26:45-52.

13. Ryding EL, Persson $\AA$, Onell C, Kvist L. An evaluation of midwives' counseling of pregnant women in fear of childbirth. Acta Obstet Gynecol Scand. 2003;1:10-7.

14. Socialstyrelsen. Nationella medicinska indikationer. Indikation för kejsarsnitt på moderns önskan [The National Board for Health \& Welfare. National medical indications. Indication for Cesarean section on maternal request]. Available online at: http://www.skl.se/ MediaBinaryLoader.axd?MediaArchive_FileID=700a61aba5d2-4a3c-8ea1-cd5902833eae $\&$ FileName $=$ Indikation $+f \%$ C3\%B6r+kejsarsnitt+p\%C3\%A5+moderns+\%C3\% B6nskan.pdf (accessed May 14, 2014).

15. Svensk förening för obstetrik och gynekologi (Swedish Association of Obstetrics \& Gynecology). Work and reference group report no. 51. Childbirth fear. Linköping: Linköping University, 2004.

16. Hildingsson I, Nilsson C, Karlström A, Lundgren I. A longitudinal survey of childbirth-related fear and associated factors. J Obstet Gynecol Neonatal Nurs. 2011;40:532-43.

17. Waldenström U, Hildingsson I, Ryding EL. Antenatal fear of childbirth and its association with subsequent caesarean section and experience of childbirth. BJOG. 2006;113:632-46.

18. Pallant J. SPSS Survival Manual: a step by step guide to data analysis using IBM SPSS. Maidenhead: McGraw-Hill, 2013.

19. Nyberg K, Lindberg I, Öhrling K. Midwives' experience of encountering women with posttraumatic stress symptoms after childbirth. Sex Reprod Healthc. 2010;1:55-60.

20. Wijma K, Wijma B, Zar M. Psychometric aspects of the $\mathrm{W}$-DEQ; a new questionnaire for the measurement of fear of childbirth. J Psychosom Obstet Gynaecol. 1998;19:84-97.

21. Rouhe H, Salmela-Aro K, Halmesmäki E, Saisto T. Fear of childbirth according to parity, gestational age and obstetric history. BJOG. 2009;116:67-73.

22. Haines H, Karlström A, Hildingsson I. Cross cultural comparison of levels of childbirth related fear in an Australian and Swedish sample. Midwifery. 2011;27:560-7.

23. Karlström A, Rådestad I, Eriksson C, Rubertsson C, Nystedt A, Hildingsson I. Caesarean section without medical reason, 1997 to 2006: a Swedish register study. Birth. 2010;37:11-20.

24. Gottvall K, Waldenström U. Does a traumatic birth experience have an impact on future reproduction? BJOG. 2002;109:254-60.

25. Lowe N. Self-efficacy for labor and childbirth fears in nulliparous pregnant women. J Psychosom Obstet Gynaecol. 2000;21:219-24.

26. Salomonsson B, Gullberg MT, Alehagen S, Wijma K. Selfefficacy beliefs and fear of childbirth in nulliparous women. J Psychosom Obstet Gynaecol. 2013;34:116-21.

27. Berentson-Shaw J, Scott KM, Jose PE. Do self-efficacy beliefs predict the primiparous labour and birth experience? A longitudinal study. J Reprod Infant Psychol. 2009;27:357-73.

28. Byrne J, Hauck Y, Fisher C, Bayes S, Schutze R. Effectiveness of a mindfulness-based childbirth education pilot study on maternal self-efficacy and fear of childbirth. J Midwifery Women's Health. 2014;59:192-7.

29. Toohill J, Fenwick J, Gamble J, Creedy D. Prevalence of childbirth fear in an Australian sample of pregnant women. BMC Pregnancy Childbirth. 2014;14:275.

30. Kjaergaard H, Olsen J, Ottesen B, Nyberg P, Dykes A-K. Obstetric risk indicators for labour dystocia in nulliparous women: a multi-centre cohort study. BMC Pregnancy Childbirth. 2008;8:45.

31. Laursen M, Hedegard C, Johansen C. Fear of childbirth: predictors and temporal changes among nulliparous women in the Danish national birth cohort. BJOG. 2008;115:354-60. 